\title{
WEIMER, Günter (2005). Arquitetura popular brasileira. São Paulo, Martins Fontes ${ }^{I}$
}

\author{
Francisco Paolo Vieira Miguel*
}

\section{O livro}

Arquitetura popular brasileira é, antes de tudo, uma obra pioneira em seu campo. Publicada em 2005 pela editora Martins Fontes, o livro pretendeu ser um modesto inventário nacional da chamada arquitetura popular. Sua publicação, inserida na Coleção Raízes - que trata de folclore, arte e mitos brasileiros -, reflete o lugar marginal que o tema "arquitetura popular", em geral, ocupa na agenda dos teóricos da arquitetura. Seu autor, o arquiteto e historiador da arquitetura, Günter Weimer, é, portanto, o mais ambicioso nos estudos dessa(s) tipologia(s) arquitetônica(s) no Brasil, o que lhe rende algum respeito.

\section{A concepção estratigráfica do homem e o impacto sobre a arquitetura}

Percebe-se, ao longo da obra, a concepção insistente da arquitetura, que hierarquiza funcionalmente os campos de "influências" sobre a construção. Por exemplo, Weimer (2005, p. 190) diz: “A semelhança de muitos tipos de encaixes realizados pelos europeus e japoneses pode ser deduzida do uso racional da madeira e de suas propriedades mecânicas, mas a diferença de outros tantos deve ser atribuída a variações culturais".

O antropólogo Clifford Geertz nos fornece as explicações:

De acordo com esta concepção, o homem é um composto de "níveis", cada um deles superposto aos inferiores e reforçando os que estão acima dele. À medida que se analisa o homem, retira-se camada após camada, sendo cada uma dessas camadas completa e irredutível a si mesma, e revelando uma outra espécie de camada muito dife-

\footnotetext{
I Esta resenha é fruto de nossa pesquisa de iniciação científica, que se intitula "Patrimônio cultural e espaço: uma etnografia da arquitetura popular na favela de Rio das Pedras". Esta pesquisa está inserida no projeto "A produção social dos patrimônios culturais: espaços e tempos de circulação e exibição" e conta com financiamento da FAPERJ. Realiza-se no âmbito do Laboratório de Antropologia da Arquitetura e Espaços (LAARES) da Universidade Federal do Rio de Janeiro, sob a orientação do Prof. José Reginaldo Santos Gonçalves.

${ }^{*}$ Graduado em Ciências Sociais - UFRJ.
} 
rente embaixo dela. Retiram-se as variegadas formas de cultura e se encontram as regularidades estruturais e funcionais da organização social. Descascam-se estas, por sua vez, e se encontram debaixo os fatores psicológicos - "as necessidades básicas" ou o-que-tem-você - que as suportam e as tornam possíveis [...] (GEERTZ, 1989, p. 49).

Ao trazer essa explicação para a Arquitetura, o que queremos é mostrar que Weimer, que representa, aqui, o discurso de parte dos arquitetos, entende o fator biológico "racionalidade" como fator universal no homem, responsável, portanto, pelas semelhanças inevitáveis no encaixe da madeira; e sobre esse, temos outro "nível", o fator "cultura" como acessório e, por isso, variável. Essa não é a única manifestação de Weimer de uma concepção estratificada. 0 autor também não a escapa quando trata das supostas diferenças entre a "arquitetura popular" e a "arquitetura erudita". Essa concepção se apresenta quando pressupõe que no nível mais elementar, o biológico, ao qual o segmento popular mais se aproximaria, haja "necessidades mais imediatas de abrigo" (WEIMER, 2005, p. 188), e que no nível mais superficial, o cultural, do qual se aproxima o erudito, a estética ou "a intenção plástica" é elemento central e varia.

Torna-se flagrante, do ponto de vista analítico, que a correlação "popular/razão prática (abrigo)" e "erudito/intenção plástica" não tem qualquer eficácia descritiva, pois, em dado momento, o autor não conseguirá dar conta de certas construção africanas ricamente decoradas ${ }^{1}$. No entanto, ela é, a sua maneira e de uma forma geral, relativamente eficaz para a oposição nativa "popular/erudito", que tenta se construir ao longo de toda a obra.

Por último, há ainda a evidência dessa mesma concepção estratigráfica, quando o autor aborda as condições “climático-ergo-ecológicas”(idem, p. 272), como se estas determinassem, necessariamente, a cultura: “[...] um clima que varia entre o árido [...] ao muito úmido [...] passando pelo semiárido [...] pelo subúmido [...] e pelo úmido [...]; [é] fator decisivo para a diversidade da arquitetura popular"(idem, p. 117) ou quando afirma "evidentemente, essa forma de construção

\footnotetext{
${ }^{1}$ Em certo momento, ele descreverá algumas casas de comunidades africanas - os augus, aucas, igalas e nsucas: "Uma rica decoração em relevos moldados e/ou esculpidos e pintados pelo lado externo, o da rua, é protegida por uma arcada circundante formada por pilares de barro. [...] 0 acabamento da casa e sua decoração abundam em sua variabilidade. [...] A exuberância decorativa não corresponde às limitações das técnicas construtivas" (WEIMER, 2005, p. 148).
} 
[com tábuas] só pôde se desenvolver em regiões onde havia abundância de madeira" (idem, p. 242).

Daí decorre um problema lógico, o de explicar o uso de palafitas mesmo onde não há escassez de terras (idem, p. 146) ou a manutenção de um certo tipo de construção que não parece condizer com o clima brasileiro (idem, p. XLIII). O que prova que, da perspectiva propriamente antropológica, a condição ambiental não é a infraestrutura necessária sobre a qual se erguem formas variadas de culturas, especificamente, a cultura material. Em outras palavras, a disposição dos recursos locais e o clima não determinarão as escolhas culturais, entre elas, o modo de se construir. Esses elementos dispostos no ambiente servem apenas como um acervo, disponível ao uso. Recordemos o exemplo de Marcel Mauss sobre as insistências de um grupo de esquimós em preservar sua tradição, renegando-se às técnicas consideradas mais "adaptadas":

\begin{abstract}
Já tivemos a ocasião de mostrar quão forte é o apego dos esquimós ao seu regime de vida, por pobre que seja; eles não imaginam sequer que possam levar uma outra existência. Parecem nunca terem feito um esforço para modificar sua técnica. Nem o exemplo dos povos vizinhos com os quais têm contato, nem a perspectiva certa de uma vida melhor são suficientes para despertar-lhes o desejo de mudar a sua. Se, como os Atapascanos e os Algonquinos, vizinhos com os quais alguns deles mantêm um comércio constante, os Esquimós do norte da América tivessem adotado a raquete para deslizar sobre a neve, em vez de seu calçado impermeável, eles poderiam em pleno inverno, perseguir por pequenos grupos a caça que só conseguem pegar no verão. Mas estão tão pegados à sua organização tradicional que nem sequer pensam em mudar (MAUSS, 2003, p. 471-472).
\end{abstract}

Nota-se no exemplo supracitado, que ainda que uma técnica seja reconhecidamente mais vantajosa pelo grupo local - assim como construir em terra, onde há terra, e não em palafitas - os grupos podem fazer escolhas culturais que não atendem à lógica da vantagem, tal qual nós a concebemos (no caso de Weimer, seriam vantagens "climática-ergo-ecológicas"), mas fazem escolhas para se distinguir de outros grupos, selecionando alguns elementos diacríticos (CARNEIRO DA CUNHA, 2009).

Na perspectiva crítica, a concepção estratigráfica do homem inviabiliza uma explicação satisfatória e deixa os casos, por ele citados, sem resposta. No entanto, percebe-se que a concepção estratigráfica dá conta, na perspectiva nativa, de elaborar uma explicação para a diversidade arquitetônica, apoiada na noção de cultu- 
ra, estabelecendo alguma ordem - ainda que frágil - no caos. E alguma ordem é sempre preferível ao caos (LÉVI-STRAUSS, 2008). A publicação de seu livro e algumas re-significações dessa obra ${ }^{2}$ corroboram para provar que tal sistema explicativo encontra alguma ressonância em seu meio.

\section{0 mito das três raças pelo código da arquitetura}

Interessante observar como se codifica o mito das três raças no pensamento do arquiteto Günter Weimer. Antes de mais nada, é preciso compreender que, para Weimer, "raça é igual à etnia e cultura" (DAmATTA, 1987, p. 84). E isso fica claro ao longo de sua obra.

Mas, segundo ele, as etnias são díspares entre si, e, para cada uma, ele fornece uma série de atribuições físicas, morais, históricas, psicológicas e culturais. Eis alguns exemplos: 1) "Se confrontarmos a população europeia com a negra, veremos que se trata da população que mais se diferenciou de sua matriz comum do Homo sapiens sapiens contra a que dele menos se diferenciou[...]"(WEIMER, 2005, p. XVII); 2) "Os negros se constituem no contigente humano mais sedentário do mundo" (idem, ibidem); 3) "[...] os indígenas sul-americanos se constituem nos maiores andarilhos conhecidos" (idem, p. XVII-XVIII); 4) "O povo português, em certo sentido, é uma espécie de síntese da cultura europeia" (idem, p. XVIII); 5) “[...] a população [negra é] a mais antiga da terra” (idem, p. XIX).

E continua: 6] "[a cultura indígena] tem um limitado desenvolvimento tecnológico da produção material" (idem, p. 42); 7) "machismo mulçumano do colonizador [português]" (idem, p. 41); 11) "cultura indígena" apresentava "qualidades que causam inveja ao homem contemporâneo, como sua admirável adaptação ecológica e a sua estrutura social isenta de disparidades causadas de explorações das forças de trabalho" (idem, p. 42); 12) "valores do mundo indígena" como a "harmônica convivência com a natureza" e a "preservação do meio ambiente." (idem, p. 57); 13) o elemento português como "conquistador [...] voraz" (idem, p. 42); 14) "os negros permaneceram em seu ambiente original; em razão

\footnotetext{
2 Entre elas, citamos o livro Arquitetura popular do Brasil de Demis Barreto, publicado em 2010, em que constam colaborações de Weimer e de outros autores.
} 
disso, suas adaptações aos novos meios ecológicos foram os menores na evolução dos cem mil anos de sua existência" (idem, p. XVII).

Todos esses atributos físicos, morais, históricos, psicológicos e culturais de cada etnia se relacionam. É o produto desse relacionamento híbrido e histórico que, de acordo com a cosmologia nativa, forma o sujeito brasileiro. Vejamos apenas alguns exemplos extraídos da obra, em que o autor trata dessas relações:

[...] alguns valores do mundo indígena foram plenamente aceitos. Entre eles, os mais evidentes foram o cultivo dos frutos da terra e o consumo desses alimentos, os banhos diários, e a rede de dormir. Por outro lado, na vida fora da casa os valores das culturas indígenas foram totalmente desdenhados, como a harmônica convivência com a natureza, a preservação do meio ambiente (idem, p. 57).

E permanecendo nos exemplos ameríndios: "ainda que a banana seja de origem asiática; seu cultivo foi totalmente absorvido pela cultura indígena" (idem, p. 62); e "[a] manutenção do binômio praça-igreja teve tamanho vigor em decorrência da interação das duas culturas [portuguesa e indígena]" (idem, p. 72).

Weimer insiste, ao longo de toda sua obra, na crença difusa de que "a formação básica da população brasileira é triíbrida" (idem, p. 39). E esse triibridismo se constituiria pelas etnias "negra" (ou "africana”), "indígena” (ou “ameríndia") e "branca" (ou "europeia", ou "ibérica” ou "portuguesa"). Chega a dizer, em certo momento, que na caatinga, no nordeste brasileiro, "da hibridação dessas três raças resultou o tipo chamado cabeça chata, em quem predomina o sangue europeu" (idem, p. 7).

Com base nesse sistema de crenças, Weimer, em uma seção que intitula "A formação étnica do Brasil", apresenta seu esquema de pensamento: "Arquitetura é um fenômeno eminentemente cultural. As interações entre as diversas culturas são difíceis de mensurar. Uma das alternativas parece ser a via do estudo da composição étnica do povo brasileiro". Feito isso, ele apresenta alguns dados do Censo 2000 do IBGE:

As estimativas oficiais da atualidade são as seguintes: brancos $=54,03 \%$, pretos $=$ $5,39 \%$, pardos $=39,94 \%$ e outros $=0,64 \%$. Esses dados, porém, não são confiáveis, visto que a avaliação foi feita à base dos conceitos emitidos pelos informantes e, portanto, carece de objetividade científica. Por isso somos forçados, a lançar mão de outros conhecimentos para obter dados que se aproximem mais das evidências dos fa- 
tos. Investigações genéticas certamente fornecem um panorama mais realista da diversidade étnica nacional (idem, p. XXI).

Fica mais do que evidente, nessa passagem, que Weimer entende que "as apreciações sobre nossa formação étnica sustentam a heterogeinidade de nossa formação cultural" (idem, p. XXII). Essas, por sua vez, sustentam a variedade arquitetônica. Ao falar dos bacongos, quimbundos, ovimbundos, lundas, quiocos e ganguelas, ele afirma: "Cada uma dessas culturas está dividida num número variável de tribos, cada qual com sua arquitetura própria” (idem, p. XIX). Confirma essa ideia quando diz que tão "complexa e contraditória foi a formação histórica do povo português" que "a consequência imediata é que a arquitetura popular portuguesa reflete essas contradições e oposições" (idem, p. 78).

Para evidenciar de forma ainda mais flagrante a ligação explícita entre a genética e a arquitetura, Weimer comenta: "Apesar do fato de a maioria dos brasileiros ter em suas veias sangue africano, parecia que a escravidão havia apagado qualquer vínculo de sua arquitetura com suas origens no continente negro" (idem, p. XXXVIII). E insiste que por "nossos concidadãos terem sangue negro em suas veias" são por isso "tributários diretos dessas civilizações [africanas]" (idem, p. 115). Mas a genética não seria uma condição apenas para a "arquitetura africana". Weimer em certo momento afirma: "Ela [a influência da arquitetura indígena] é mais ou menos presente na exata proporção da mestiçagem com o indígena" (idem, p. 65).

E é nesse sentido, de associação da etnia às formas arquitetônicas, técnicas de construção e usos de determinados materiais, que se percorre toda a obra de Weimer.

O antropólogo Lévi-Strauss, contudo, alerta-nos para essa perigosa ligação de atributos genéticos aos aspectos culturais:

Embora o desenvolvimento da genética deva permitir a superação definitiva da noção de espécie, o que a tornou - e a torna ainda - válida para os naturalistas é o fato de cavalos gerarem efetivamente cavalos e assim, através [sic] de um número suficiente de gerações, o Equus caballus ser verdadeiramente descendentes do Hipparion. A validade histórica das reconstruções dos naturalistas é garantida, em última análise, pelo elo biológico da reprodução. Ao contrário, um machado nunca engendra outro machado; entre dois instrumentos idênticos, ou entre dois instrumentos diferentes mas cuja a forma de algum modo se assemelha, houve e haverá sempre uma descontinuidade ra- 
dical, decorrente do fato de que um não provém do outro, e sim, cada um deles, de um sistema de representação (LÉVI-STRAUSS, 2008, p. 16-17).

Para entendermos as explicações e a crítica do antropólogo no âmbito de nosso trabalho, basta trocar a palavra "machado", em seu enunciado, por "construção", ou "casa" ou "ambiente construído". Tomando esses como nossos objetos, nossa crítica se evidenciará.

Não entraremos no mérito das "origens" do mito das três raças, ou do porquê de sua vasta ressonância no Brasil. Damatta (1987) já o fez. Mas entendamos que, do ponto de vista analítico, trata-se do "[...] conhecimento social sendo reduzido a algo natural como 'raças', 'miscigenação' e traços biologicamente que tais 'raças' seriam portadoras" (DAMATTA, 1987, p. 60). 0 que gera "[...] um esquema onde o biológico se confunde com o social e o cultural, permitindo assim realizar uma permanente miopia em relação à nossa possibilidade de autoconhecimento" (idem, p. 85). Mas que do ponto de vista nativo,

[...] essa fábula é importante porque, entre outras coisas, ela permite juntar as pontas do popular e do elaborado (ou erudito), essas duas pontas de nossa cultura. Ela também permite especular, por outro lado, sobre as relações entre o vivido (que é frequentemente chamado de popular e o que nele está contido) e o concebido (o erudito ou o científico - aquilo que impõe a distância e as intermediações) (idem, p. 62).

Não estamos negando aqui a contingência histórica da importância dessas três raças no Brasil, "mas há uma distância significativa entre a presença empírica dos elementos e seu uso como recursos ideológicos na construção da identidade social, como foi o caso brasileiro" (idem, p. 62-63). Disse-nos Damatta ainda:

Se no plano social e político o Brasil é rasgado por hierarquizações e motivações conflituosas, o mito das três 'raças' une a sociedade num plano 'biológico' e 'natural', domínio unitário, prolongado nos ritos de Umbanda, na cordialidade, no carnaval, na comida, na beleza da mulher (e da mulata) e na música... (idem, p. 70).

E na "arquitetura popular", inclui Weimer.

Apesar de operar com o mito da três raças, devemos marcar que Weimer reelabora tal mito, quando tem de admitir que outras etnias também participaram 
da formação cultural do Brasil3: "A presença holandesa em território brasileiro em tempos longínquos visa basicamente registrar que o fenômeno Brasil não deve ser referido apenas a uma formação do trinômio indígena/português/negro. A realidade foi muito mais complexa" (WEIMER, 2005, p. 157). Por isso, o autor dedica um capítulo inteiro às "contribuições de imigrações europeias não ibéricas", no qual, curiosamente, inclui as supostas "contribuições" japonesas, além das "contribuições" holandesas, alemãs, italianas, polonesas e russas. Nesse capítulo ele tenta dar conta de toda a variedade de "influências" que escapam ao seu sistema tríade das contribuições indígenas/ibéricas/negras. Essa relativização não revoga, porém, seu esquema classificatório, que privilegia as categorias raciais como chaves explicativas para o entendimento de uma arquitetura "brasileira".

\section{Conclusão}

É antropologicamente rentável demonstrar o caráter etnocêntrico de determinadas elaborações que se pretendam universais e científicas (ainda que se restrinjam ao seu âmbito nacional, como faz Weimer, em seu papel de teórico). As categorias que esse autor tenta impor ao campo, como "arquitetura", "popular", "brasileira" etc., não encontram ressonância no próprio campo, e, do ponto de vista analítico, são incapazes, como vimos, de formar uma classificação satisfatória. São toleradas, portanto, apenas como categorias nativas da cosmologia de parte daquele grupo profissional, os arquitetos. Essas categorias dão conta (ou prestam-se a dar), na cosmologia nativa, de organizar a suposta desordem em que se encontraria esse fenômeno da arquitetura não acadêmica, no mundo (acadêmico) de Weimer.

Por fim, Arquitetura popular brasileira tem seu mérito por trazer a questão da cultura material para o debate e por constituir um acervo respeitável de tipos diversificados de habitação no Brasil e alhures. Além disso, com base nas categorias que Weimer mobiliza, é possível desvendar o amplo sistema simbólico que ope-

\footnotetext{
3 "A presença de europeus não ibéricos no Brasil colonial é muito importante para o entendimento de algumas características de certas cidades que fogem da tradição lusitana” (WEIMER, 2005, p. 153).
} 
ra em parte de sua comunidade profissional ${ }^{4}$, mas que, definitivamente, não atende ao seu objetivo científico de formular uma teoria que dê conta de controlar o suposto fenômeno da "arquitetura popular", haja vista as já aqui mencionadas tentativas frustradas de classificação.

\section{Referências}

Antogini, G.; SpInI, T. (2008). "Arquitectura”. In: Bonte, P.; IZARD, M. Diccionario Akal de Etnología y Antropologia. Madrid, Ediciones Akal.

Barreto, D. I. S.; Holzer, W.; Medeiros, H.; Weimer, G. (2010). Arquitetura popular do Brasil. Rio de Janeiro, Bom Texto.

Carneiro da Cunha, M. (2009). Cultura com aspas. São Paulo, Cosac \& Naify.

DAMATTA, R. (1987). "Digressão: A fábula das três raças, ou o problema do racismo à brasileira". In: DAMATTA, R. Relativizando: uma introdução à antropologia social. Rio de Janeiro, Rocco.

GeERTZ, C. (1989). A interpretação das culturas. Rio de Janeiro, Editora Guanabara Koogan.

LAWREnCE, D. (2009). “Architecture”. In: BARFIELD, T. (Ed.). Dictionary of Antropolgy. Blackwell Publishing.

LÉVi-STRAuSS, C. (2008). Antropologia Estrutural I. São Paulo, Cosac \& Naify.

MAuss, M. (2003). "Ensaio sobre as variações sazonais das sociedades esquimós" In:___. Sociologia e Antropologia. São Paulo, Cosac \& Naify.

RAPOPORT, A. (1977). House form and culture. New Jersey, Prentice Hallm Upper Saddle River.

Weimer, G. (2005). Arquitetura popular brasileira. São Paulo, Martins Fontes.

Recebido em dezembro/2010

Aprovado em agosto/2011

4 Trabalho a que nos dedicamos e que já se encontra em processo de publicação. 